\title{
Contamination of formula milk
}

\author{
Sri Lanka Journal of Child Health, 2012; 41(4):154-156
}

(Key words: formula milk; contamination)

It has been a well established contention that human breast milk is the perfect nutrition for all babies up to the age of six months of life. It provides all the necessary nutrients for initial growth, progressive mental development and maintenance of good health. In addition, the unique qualities of this golden elixir of life, especially the protective effects against several infections, are well documented.

Under certain very special circumstances within the first six months of life and as a complementary food after that time, it may be necessary to provide formula milk derived from cow milk to children. These are provided either in a liquid whole milk type or as dried powdered milk which needs to be reconstituted in water prior to feeding. When prepared according to the manufacturer's instructions provided on the pack, these have been generally considered to be safe. Many parents and care-providers have regularly placed infinite faith in the goodness and safety of these products. There is of course the possibility of the formula milk feeds being contaminated during the process of domestic preparation due to unhygienic methods but these are largely preventable in most cases by adhering strictly to the instructions provided.

Nonetheless, it is not generally appreciated that formula milk powders are not completely sterile ${ }^{1}$. In fact, a certain number of specified microorganisms are permitted in the final formulation of the finished product. None of these allowed microbes are of the potentially pathogenic variety and some, such as the probiotics, are considered to be beneficial. The stipulated standards are given in Codex Alimentarius Standards ${ }^{2}$, European Union Regulations ${ }^{3}$ and the Sri Lanka Standards Institute documents ${ }^{4}$. All these have one thing in common i.e. the provision of strict guidelines to ensure that potentially pathogenic microorganisms do not contaminate these milk formulae. In addition, non-microbe types of additives are also very strictly controlled by statutory regulations in all countries.

However, in stark contrast to all these well regulated considerations, the possibility of these milk powders being tainted at the original manufacturing level to be the cause of noninfective types of diseases due to other undesirable contaminants and even a source of certain serious infections has come to light over the last few decades. These are undoubtedly rare but are of considerable concern in the perspective of the severity of the problems caused by them.

The best publicised episode of chemical contamination is the well documented episode of the addition of the illegal substance melamine to formula milk $^{5}$. In 2008, increasing numbers of infants and young children in China started to develop unexplained urinary tract stones. The reason for this most unusual epidemic was identified as the addition of the so called "protein essence" melamine to raw milk to falsely increase the protein content after dilution. The raw milk was then processed to produce the milk powder. High enough concentrations of melamine in the milk feeds, after absorption, led to the formation of crystals and stones in the urinary tract. Over 20 dairy companies were incriminated in this saga of a most unpleasant incident. In the same year traces of melamine were found in the formula milks in Canada and the United States of America. These levels were much less than those reported in China, where levels of melamine contamination had reached as much as 2,500 parts per million, about 10,000 times higher than the recorded US levels.

Serious infections caused by pathogenic microorganisms that have contaminated the formula milk powders have been quite well documented. Quite a while ago, an outbreak of diseases caused by lactose-non-fermenting Salmonella virchow strains attributed to contaminated infant formula milk was reported from Spain ${ }^{6}$. In recent years, at least 6 outbreaks of Salmonella infection in infants that have been linked to the consumption of powdered infant formula have been reported. Many of these outbreaks were identified because the Salmonella strains were unique in some way (e.g. a rare serotype), and a well-established Salmonella surveillance network, supported by laboratories capable of serotyping isolates, was in place. Another common feature of the outbreaks was the low level of salmonellae detected in the implicated formula. In fact salmonellae may be missed in routine testing. These outbreaks are likely represent only a small proportion of the actual number of Salmonella infections in infants that have been linked to powdered infant formula ${ }^{7}$. 
There have been many recent reports of more serious infections with Enterobacter (Cronobacter) sakazakii associated with contaminated formula milk. Multiplication of Enterobacter sakazakii in prepared formula feeds can cause devastating sepsis, particularly in the first 2 months of life. In approximately 50 published case reports of severe infection, there are high rates of meningitis, brain abscesses and necrotizing enterocolitis, with an overall mortality varying from 33 to 80 percent $^{1}$. Enterobacter sakazakii represents a significant risk to the health of neonates. This bacterium is an emerging opportunistic pathogen that is associated with rare but life-threatening cases of these infections in premature as well as full-term infants and infants aged less than 28 days are considered to be most at risk $^{8}$. The average annual number of invasive Cronobacter infections worldwide increased from 1.5 in $1958-2003$ to 4.3 in 2004 2010. A review of 68 cases from around the world during 1958-2003 and another 30 from 2004-2010, all in children without underlying disorders, revealed that 90 percent of infected infants had received powdered infant formula or human milk fortifier, and this proportion did not differ significantly between time periods ${ }^{9}$.

In view of these recent developments, more and more emphasis is now placed on different methods of sterilising milk that is used to prepare powdered formulae. Milk could be heat treated to maintain optimal bacteriological quality of the product. Pasteurization typically uses temperatures below boiling, since at very high temperatures, casein micelles will irreversibly aggregate, or "curdle" ${ }^{10}$. However, heat treatment could also be undertaken through either retort sterilization or hightemperature short-time (HTST) treatment. Recently, ultrahigh-temperature treated formula has become more commonly used. If powdered formula is made from such treated milk, then spray drying would be required in addition. Retort sterilization is a traditional retort sterilization method that uses $10-15$ minutes treatment at $118^{\circ} \mathrm{C}$. Ultrahigh-temperature (UHT) is a method that uses a brief (2-3 seconds) treatment at $142^{\circ} \mathrm{C}$. Because of the short time used, there is little protein denaturation but the process still ensures sterility of the final product.

In addition, the current recommendation of domestic preparation of formula milk powders include washing hands with soap and water prior to preparing the feed, boiling water and allowing the boiled water to cool down to no less than $70^{\circ} \mathrm{C}$ and adding the recommended amounts of the milk powder. In practice, this means water that has been left, covered for less than 30 minutes after boiling $^{11}$. The assumption is that in the very rare event of the powder being contaminated with potentially pathogenic organisms, the temperature of the water would help to kill them prior to the feed being given to the child.

All these measures are instituted for the safety of children. All nations have an unequivocal responsibility to ensure that such considerations get priority in their agenda. It must be emphasised that serious events and fatalities attributed to contaminated milk formulae are totally unacceptable in the context of safety of children. Milk food industry has a tremendous responsibility to ensure that safety concerns regarding milk formulae are properly addressed at all times. Even if one child dies of a catastrophe resulting from contaminated milk formula, it is just one death too many.

\section{References}

1. Agostoni C, Axelsson I, Goulet O, Koletzko B, Michaelsen KF, Puntis JWL et al. Preparation and handling of powdered infant formula: A commentary by the ESPGHAN Committee on Nutrition. Journal of Pediatric Gastroenterology \& Nutrition 2004; 39(4): 320-2. http://dx.doi.org/10.1097/00005176200410000 $-00002$

2. Codex Alimentarius. 2009. Code of hygienic practice for powdered formulae for infants and young children, CAC/RCP 66-2008. Available from:

www.codexalimentarius.org/standards/list-of standards/en/?no cache $=1 \quad$ [Accessed 18 October 2012]

3. European Union, 2005. Commission regulation (EC) No 2073/2005 of 15th November 2005 on microbiological criteria for foodstuffs, Official journal of the European Union, 22 December 2005. Available from: www.eurlex.europa.eu/LexUriServ/LexUriSer v.do?uri-CELEX:32005R2073:EN:HTML

[Accessed 18 October 2012]

4. Sri Lanka Standard 651:2007. UDC 637.144. pub. Sri Lanka Standards Institute, Colombo 8, Sri Lanka.

5. Chen Jun-shi. A worldwide food safety concern in 2008-melamine-contaminated infant formula in China caused urinary tract stone in 290,000 children in China. Chinese Medical Journal 2009; 122(3):243-4.

6. Usera MA, Rodriguez A, Echeita A, Cano R. Multiple analysis of a foodborne outbreak caused by infant formula contaminated by an 
atypical Salmonella virchow strain. European Journal of Clinical Microbiology \& Infectious Diseases 1998; 17(8):551-5.

http://dx.doi.org/10.1007/BF01708617

7. Cahil SM, Wachsmuth IK, Costarrica M de L, Embarek PKB. Powdered infant formula as a source of Salmonella infection in infants. Clinical Infectious Diseases 2008; 46(2): 26873.

http://dx.doi.org/10.1086/524737

8. Drudy D, Mullane NR, Quinn T, Wall PG, Fanning S. Enterobacter sakazakii: An emerging pathogen in powdered infant formula. Clinical Infectious Diseases 2006; 42(7):996-1002.

http://dx.doi.org/10.1086/501019
9. Jason J. Powdered infant formula can harbour rare but deadly Cronobacter. Available from: http://www.medscape.com/viewarticle/772247

10. Pasteurization. Available from: http://en.wikipedia.org/wiki/Pasteurization [Accessed 20th October 2012]

11. Guidance on safe preparation, storage and handling of powdered infant formula. Available from: http://www.infantfeeding.info/preparation.htm [Accessed 21st October 2012]

B J C Perera

Joint Editor 